\title{
Breakage Characteristics of Quartz Sand Based on Ring Shear Tests: Implications for the Fragmentation Processes of Rock Avalanches
}

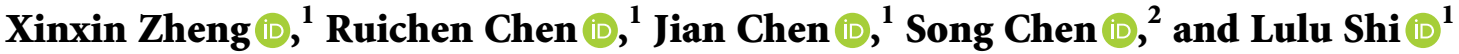 \\ ${ }^{1}$ School of Engineering and Technology, China University of Geosciences Beijing, Beijing 100083, China \\ ${ }^{2}$ School of Urban Geology and Engineering, Hebei GEO University, Shijiazhuang 050031, China \\ Correspondence should be addressed to Jian Chen; jianchen@cugb.edu.cn and Song Chen; chennsongg@163.com
}

Received 7 December 2021; Accepted 16 December 2021; Published 13 January 2022

Academic Editor: Bing Bai

Copyright (C) 2022 Xinxin Zheng et al. This is an open access article distributed under the Creative Commons Attribution License, which permits unrestricted use, distribution, and reproduction in any medium, provided the original work is properly cited.

To investigate the effects of internal shear fragmentation on dry granular flow, in this study a series of ring shear tests were performed on quartz sand samples under different normal stresses $(100 \mathrm{kPa}, 200 \mathrm{kPa}$, and $300 \mathrm{kPa})$, shear displacements $(3 \mathrm{~m}, 5 \mathrm{~m}$,

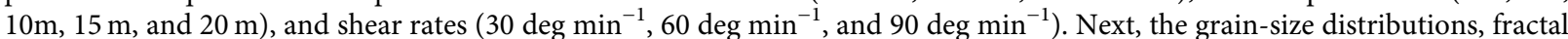
dimensions, and microcharacteristics of the quartz sand before and after the experiments were compared and analyzed. The study results show that grain breakage under shearing preferentially occurs at the edges of the particles and forms a bimodal distribution in frequency grain-size distribution curves, which is consistent with observations of rock avalanches. The fine particles prevent the coarse particles from breaking, in turn leading to the ultimate grain-size distribution and stable fractal dimension (2.61) of quartz sand at relatively small shear displacements compared with the travel distance of rock avalanches. The results of this study suggest that the fragmentation of rock avalanches during the shear spread stage may be far less significant than previously believed. Therefore, the fragmentation effect is not considered to be a major factor of the hypermobility in the late stage of rock avalanches.

\section{Introduction}

Rock avalanches are distinguished by their massive scale, rapid speed, and extensive travel distances, all of which are extremely dangerous and destructive $[1,2]$. Therefore, it is of great significance to clarify the kinematic characteristics and mechanism of rock avalanches for their monitoring and early warning.

Since Heim conducted a series of field investigations and described the hypermobility of the debris flow of the Elm landslide which occurred in Switzerland in 1881 [3], various theoretical models have been proposed to explain the highspeed and long-runout movement mechanism of rock avalanches [4], including the cushion of trapped air $[5,6]$, frictional melting [7-9], substrate liquefaction [10, 11], dynamic fragmentation [12-14], acoustic fluidization $[15,16]$, and momentum transfer motion [17]. However, these hypotheses are still widely debated, due to the rarity of the field evidence [18]. The fragmentation hypothesis proposed by Davies may be the most promising hypothesis at present [19], due to the fact that intense fragmentation is characteristic of rock avalanches. Recently, increasing numbers of studies regarding dynamic fragmentation have been published [20-23].

Based on the fact that granular flow is influenced by multiple factors, dynamic fragmentation is more of a complex process controlled by a nonsingle mechanism [24-28]. Most fragmentation occurs during the early stage of movement, which is dominated by collision [29]. Further fragmentation of the block is caused by factors such as shearing during later transport, and it is unevenly distributed throughout the landslide body [30].

A typical facies model of rock avalanches has been proposed by Dufresne et al. [30]. The significant differences in the grain-size distribution of different facies suggest that the fragmentation process in rock avalanches is complex. 
Some studies have explored the fragmentation characteristics and mechanisms based on the sedimentation characteristics of the rock avalanches. For example, some researches have indicated that the rock avalanches exhibit grain size differentiation with the accumulation of distance; that is, the fragmentation gradually increases with the development of the rock avalanches movement process $[10,27,30-33]$. Hewitt [34] pointed out that rugged topography exerts an essential influence on the morphology and structure of rock avalanche accumulations and that topographic obstruction not only limits the fragmentation process in rock avalanches but also creates different facies. Shugar and Clague [27] and Dufresne et al. [30] suggested that lithology is partially responsible for the differences occurring in particle size fractions. In addition, Perinotto et al. [35] compared the morphological characteristics of particles in rock avalanche deposits and identified the fact that the particle refinement after reaching a certain level of particle collisional fragmentation during rock avalanche is mainly dependent on the shear effect. However, similar to the results on the grain size of carapace facies [27, 29], numerous studies have indicated that the grain-size distribution did not vary significantly with the travel distance [36-38].

These inconsistent findings have indicated that the sedimentary characteristics of rock avalanches remain ambiguous, and a clear model for fracture characteristics is lacking. These field investigations are influenced not only by the original lithology and topography but also by the scarcity and limitation of outcrops. Therefore, it is necessary to conduct tests in a more ideal and simplified environment.

More recently, some studies had revealed the frictional weakening with the velocity [39-41], yet their explanations have differed from one another. Wang et al. [40] observed the frictional weakening is caused by thermal pressurization and moisture fluidization, $\mathrm{Hu}$ et al. [41] held there is thixotropy in dry particle flow under a high-speed shearing, and Jiang et al. [39] proposed that the dynamic fragmentation and elastic energy release were the causes of the frictional weakening.

There have also been an increasing number of ring shear tests carried out to study the fracture characteristics of dry granular flow. For example, the tests carried out by Dubovskoi et al. [42] revealed that a small static load combined with shear could cause significant particle fragmentation. In addition, Zhang and McSaveney [28] suggested that shear displacement and normal stress are the factors affecting fragmentation, rather than the shear strain rate. The test results for the landslide soils roughly indicated that the grain size limit appears to occur at a displacement of $3 \mathrm{~m}$ [43]. Furthermore, Coop et al. [44] noted that stable grading exists in carbonate sand under large displacement shear. Although the abovementioned studies have presented the grain size characteristics, they have not systematically explained the elevation process or the mechanism of fragmentation.

The characteristics of the grain-size distribution and fragmentation limits are very critical issues, as they are significant for understanding the fragmentation and emplacement

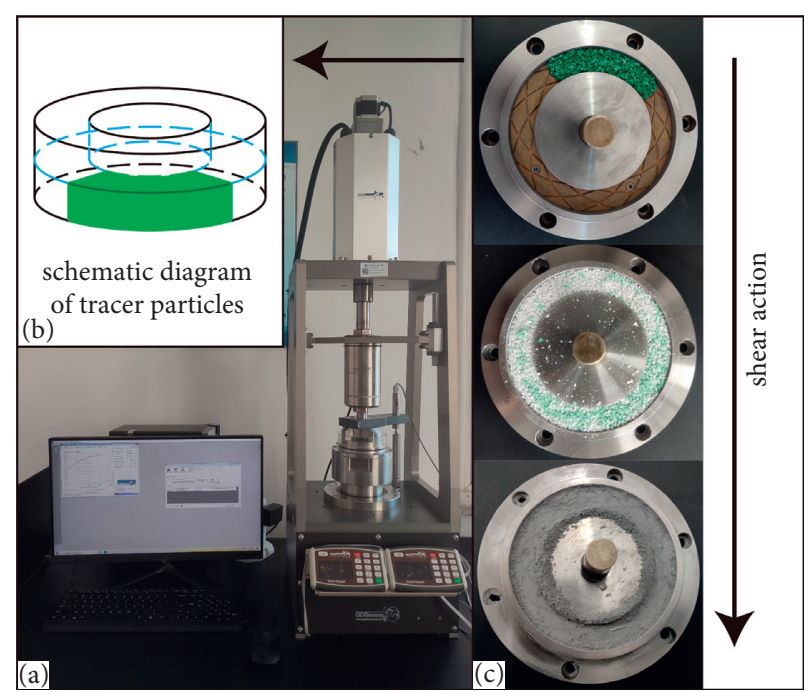

FIgURE 1: Diagrams of the experimental apparatus. (a) GDS ring shear instrument. (b) Schematic diagram of the initial position of the tracer particles. (c) Photograph of tracer results.

TABLE 1: Parameters of the instrument.

\begin{tabular}{lccc}
\hline & Maximum load & Distinguishability & Accuracy (\%) \\
\hline Axial force & $5 \mathrm{kN}$ & $1 \mathrm{~N}$ & 0.2 \\
Torque & $200 \mathrm{Nm}$ & $0.001 \mathrm{Nm}$ & 0.2 \\
\hline
\end{tabular}

processes. Meanwhile, the fragmentation limit also determines to a certain extent whether the dynamic fragmentation could continue throughout the emplacement process of rock avalanches. Previous complex field findings and experimental results have prompted us to conduct a more systematic study regarding the fragmentation characteristics under shear. We have yet to explore the process of disintegration and collision fragmentation in the early stage of rock avalanches, nor have we explored the rheological weakening [41] or frictional weakening under thermalization $[40,45,46]$. The main purpose of the present study was to explore the characteristics of shear fragmentation and its effect. We systematically analyzed the results of long-displacement ring shear tests in terms of shear stress variation, grain-size distribution and fractal dimension variation, and particle microscopic characteristics, so as to provide insights regarding the shear fragmentation effect of rock avalanches.

\section{Methodology}

2.1. Materials and Experiment Setups. The experiment aimed to investigate the fragmentation characteristics of dry granular flow during the large-displacement shear process. A GDS(RST) ring shear instrument was used in this study to simulate the continuous strains of granular flow (Figure 1(a)). The inner and outer ring diameters of the shear box are $70 \mathrm{~mm}$ and $100 \mathrm{~mm}$, respectively, with a height of $5 \mathrm{~mm}$ and an area of $0.004 \mathrm{~m}^{2}$. The other detailed instrument parameters are listed in Table 1.

Dry quartz sand with angular shapes was used in this experiment. With the exception of the tests of different grain 
TABLe 2: Details of the tests conducted.

\begin{tabular}{lcccc}
\hline No. & Normal stress $(\mathrm{kPa})$ & Shear rate $\left(\right.$ deg $\left.\mathrm{min}^{-1}\right)$ & Shear rate $\left(\mathrm{mm} \mathrm{s}^{-1}\right)$ & Shear displacement $(\mathrm{m})$ \\
\hline 1 & $100 / 200 / 300$ & 60 & 0.74 & 15 \\
2 & 200 & $30 / 60 / 90$ & $0.37 / 0.74 / 1.11$ & 15 \\
3 & 200 & 60 & 0.74 & $3 / 5 / 10 / 15 / 20$ \\
\hline
\end{tabular}

sizes, all tests used 1-1.5 mm coarse quartz sand, which could provide a more distinct difference in the fragmented process than well-graded sand grains. Compared to calcareous sand, quartz sand has a more uniform angular shape and greater density $\left(2,000 \mathrm{~kg} / \mathrm{m}^{3}\right)$, making it more closely resemble rock fragments [47]. In addition, quartz sand can provide more microscopic information to reveal the dynamic processes of fragmentation $[48,49]$. In the experiments, $30 \mathrm{~g}$ of quartz sand granules was weighed and placed evenly throughout the shear box, and the initial porosity of the specimens was controlled at $43.47 \%$. The tracer experiments showed that the dyed particles were dispersed in both the horizontal and longitudinal directions after the shearing (Figures 1(b) and 1(c)). Table 2 illustrates the three test groups with different normal stresses, shear rates, and shear displacements. The normal stresses of $100 \mathrm{kPa}, 200 \mathrm{kPa}$, and $300 \mathrm{kPa}$ in group 1 , respectively, correspond to the burial depths of approximately $5 \mathrm{~m}, 10 \mathrm{~m}$, and $15 \mathrm{~m}$. The data recording interval was $1 \mathrm{~s}$.

2.2. Grain-Size Distribution and Fractal Dimension. The grain-size distributions of the samples were determined using a HELOS H2566 laser grain size analyzer (0.01 to $3,500 \mu \mathrm{m})$. The average value of 10 measurements of each sample was taken as the final grain-size distribution. The cumulative grain-size distributions and frequency grain-size distributions were both used to qualitatively assess the differences in grain size.

The fragmentation of rock material always produces small-size particles, and these continue to be crushed to produce even smaller particles, which is generally considered to be self-similar behavior $[25,50]$. The fractal dimension, $F D$, was employed to quantitatively determine the degree of shear fragmentation. In order to calculate the $F D$, the relationship between the mass percentage and FD is reconstructed as follows:

$$
\begin{array}{r}
\frac{M(r)}{M\left(r_{0}\right)}=\frac{\int_{0}^{r} 4 / 3 \pi \rho x^{3} d\left(N / N_{0}\right)}{\int_{0}^{r_{\max }} 4 / 3 \pi \rho x^{3} d\left(N / N_{0}\right)}, \\
\frac{M(r)}{M\left(r_{0}\right)}=\left(\frac{r}{r_{\max }}\right)^{3-F D},
\end{array}
$$

where $M(r)$ is the total mass of particles with a size larger than $r, M\left(r_{0}\right)$ is the total mass of particles, $r_{0}$ is related to the average grain size, $N_{0}$ is the total number of particles, $r_{\text {max }}$ is the maximum particle size, and FD is the fractal dimension. In a double logarithmic coordinate system of $M(r) / M\left(r_{0}\right)-r$, the slope of the regression line fitted at each point is equal to $3-F D$ [25].
2.3. Morphometric and Microscopic Method. The elongation ratio and circularity were used to quantitatively assess the morphological changes of the particles before and after shearing. The elongation ratio was defined as $I / L$ ( $L$ is specified as the longest dimension of the particle and $I$ is the longest dimension perpendicular to $L$ ). The circularity was defined as the ratio of the area of a particle to the area of a circle with the same circumference $C=4 \pi A / d^{2}$ [51], where $A$ denotes the two-dimensional projected area of the particle and $d$ denotes its equivalent perimeter. As the particles approach a circular form, the values increase from 0 to 1 . The above analysis was performed based on optical microscope magnification photographs. Next, the surface textures of quartz sand were observed and photographed using scanning electron microscopy (Zeiss supra 55), after having been sputter-coated with gold by Quorum SC7620. The frequency of the microtextures was then counted for analysis [52-54].

\section{Results}

3.1. Shear Strength. The influence of the particle size (0.25-0.5 mm, $0.5-1 \mathrm{~mm}, 1-1.5 \mathrm{~mm}$, and $1.5-2 \mathrm{~mm})$ was tested under normal stress of $200 \mathrm{kPa}$ at a shear rate of $60 \mathrm{deg}$ $\min ^{-1}$. Figure 2 illustrates the control of particle size on shear strength. The smaller the average particle size was, the greater the shear strength would be, although the increase was small $(0.5-3 \mathrm{kPa})$.

Figure 3 presents the shear stress-displacement relationship for $1-1.5 \mathrm{~mm}$ quartz sand at a shear rate of $60 \mathrm{deg}$ $\min ^{-1}$, but under the normal stresses of $100 \mathrm{kPa}, 200 \mathrm{kPa}$, and $300 \mathrm{kPa}$. Clearly, the shear strength of quartz sand particles increases with the normal stress. In addition, a slight increase in shear strength with displacement is observed in Figure 3, where the shear strength changes from $80 \mathrm{kPa}$ to $85 \mathrm{kPa}$ under $300 \mathrm{kPa}$. It can be seen that when the maximum size of the particles is reduced, the shear stress increases by $1 \%$ to $6 \%$.

The relationship between the strain rate and shear stress was also tested and analyzed (Figure 4). Consistent with the experimental results of Zhang and McSaveney [28], the difference in shear strength of the samples at different shear rates in this study was also very minimal, with $a<1 \%$ change in the mean values. The most noteworthy aspect is that all of the shear stress-displacement curves exhibit significant fluctuations, reaching up to $24 \%$ of the respective average values.

3.2. Changes in Grain-Size Distribution and Fractal Dimension after Shearing Action. Previous research has shown that particle fragmentation is independent of the 


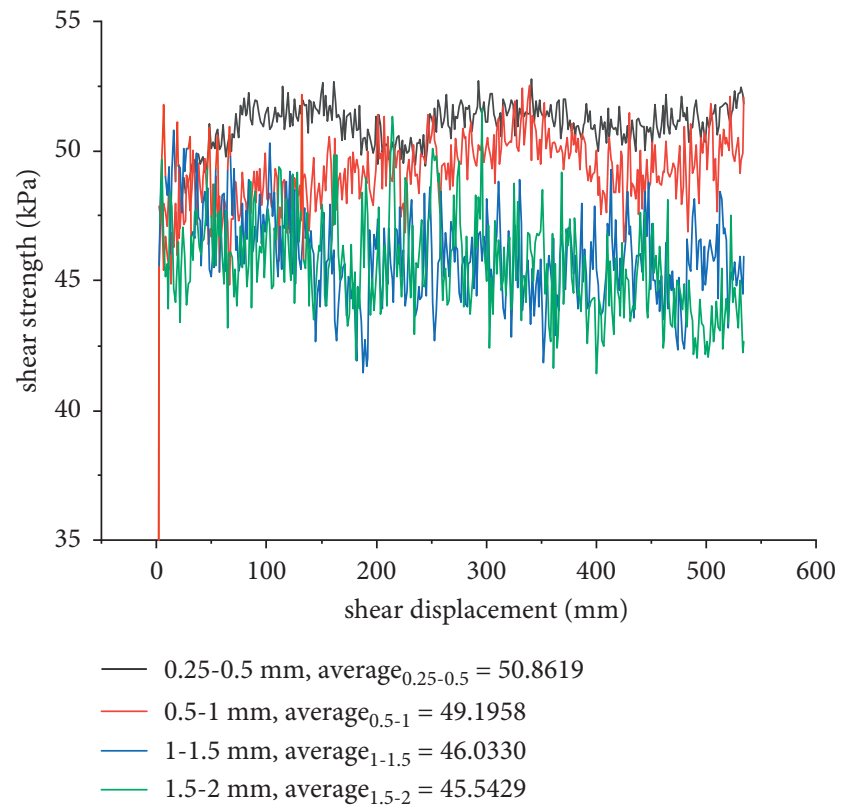

(a)

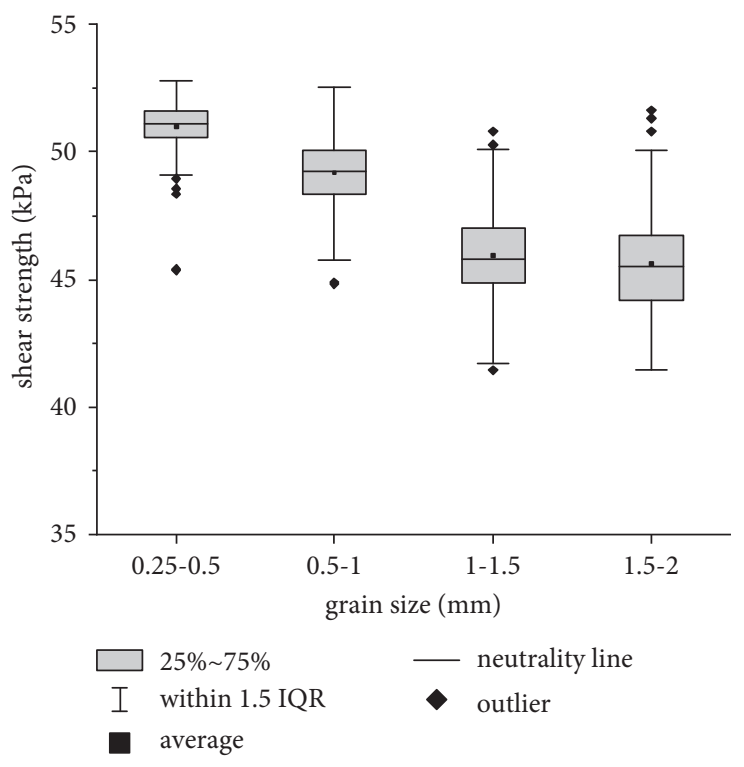

(b)

FIGURE 2: Distribution of shear strength in different grain sizes. (a) Shear stress-displacement curves of particles with different grain sizes. (b) Box plot of shear strength for different grain sizes.

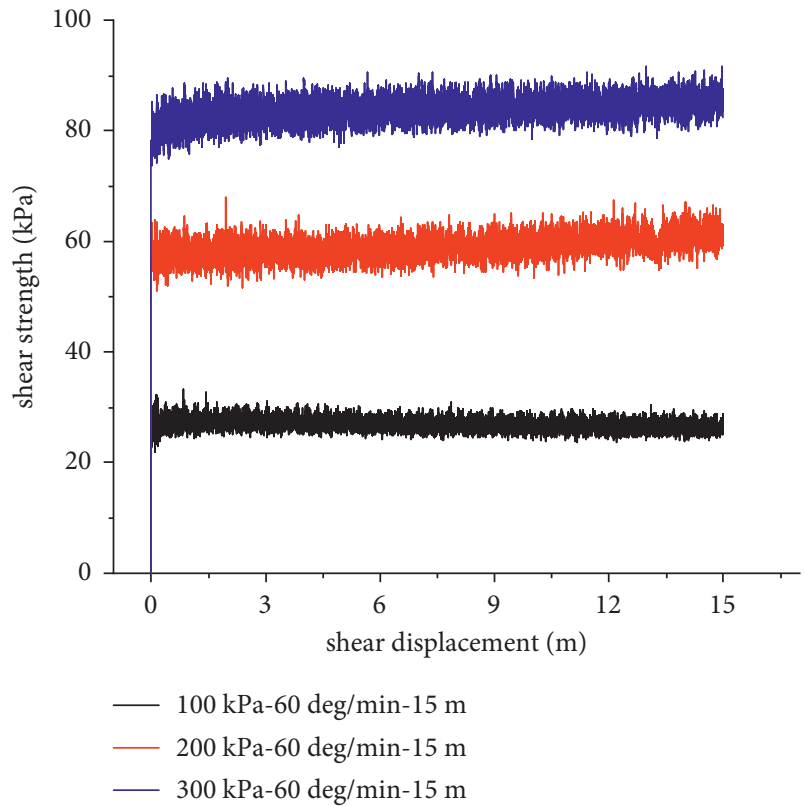

FIGURE 3: Shear stress-displacement curves under different normal stresses.

shear rate and is only related to the normal stress and shear displacement [28]. In order to further investigate the characteristics of the shear fragmentation, experiments similar to the previous study were first carried out. Figure 5 presents the cumulative grain-size distribution curves and the frequency grain-size distribution curves at the same shear rate $(60 \mathrm{deg} / \mathrm{min})$ and shear displacement $(15 \mathrm{~m})$, but under normal stresses of $100 \mathrm{kPa}, 200 \mathrm{kPa}$, and $300 \mathrm{kPa}$. The results reveal that the shear process, respectively, produced

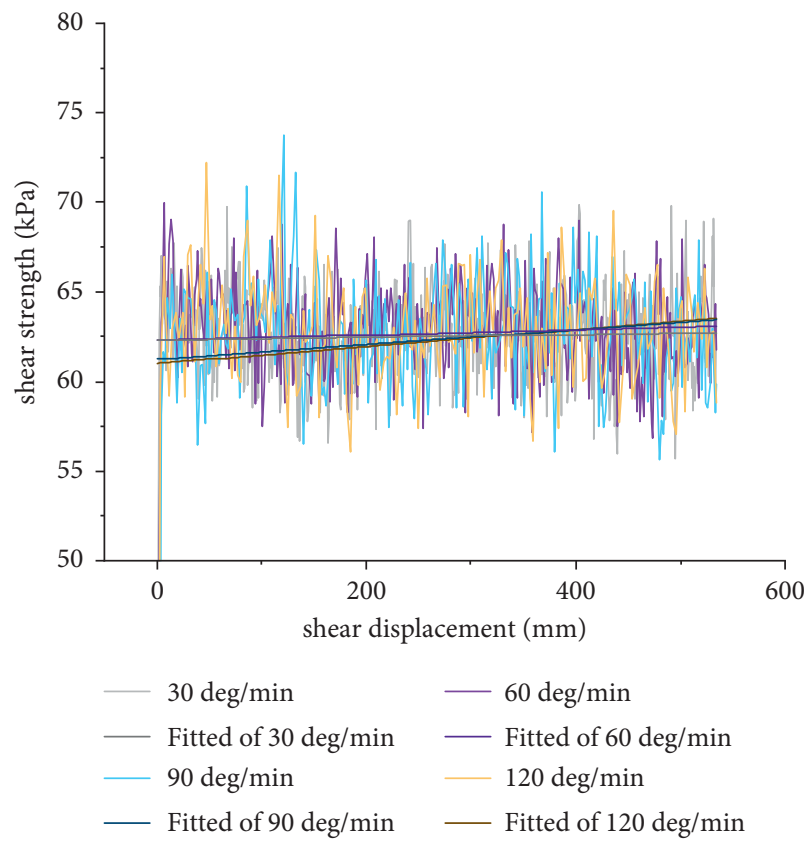

FIGURE 4: Shear stress-displacement curves at different shear rates.

$2.79 \%, 27.27 \%$, and $47.83 \%$ of the fragments below $100 \mu \mathrm{m}$ (Figure 5(a)) and that the coarse peak shown in Figure 5(b) clearly shifted to the left $(1,593.86 \mu \mathrm{m}, 936.59 \mu \mathrm{m}$, and $657.27 \mu \mathrm{m})$. In addition, the conclusion reached by Zhang and McSaveney [28], namely, that the shear strain rate does not affect the grain-size distribution, is also verified here (Figure 6).

Figure 7 presents the evolution of grain-size distributions with shear displacements $(200 \mathrm{kPa}, 60 \mathrm{deg} / \mathrm{min})$. At a shear 


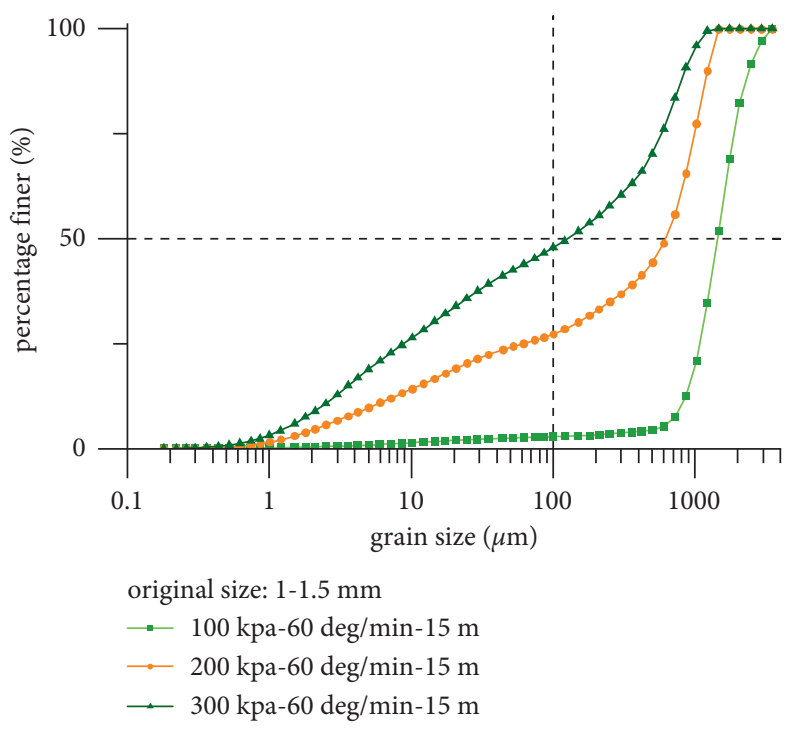

(a)

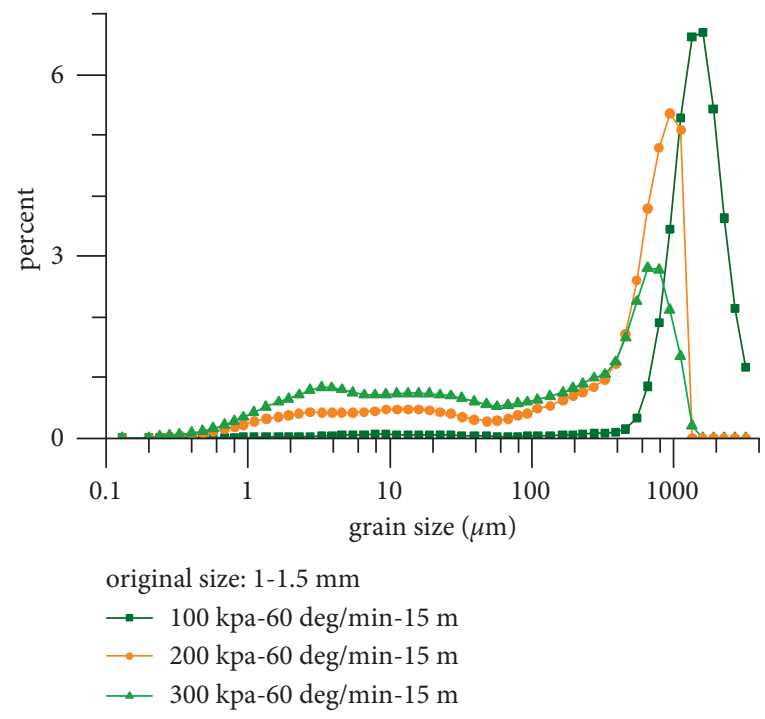

(b)

FIgURE 5: Evolution of grain size distribution with normal stresses. (a) Cumulative grain-size distribution curves after shearing at $15 \mathrm{~m}$ at a shear rate of $60 \mathrm{deg} / \mathrm{min}$ under the normal stresses of $100 \mathrm{kPa}, 200 \mathrm{kPa}$, and $300 \mathrm{kPa}$. (b) Frequency grain-size distribution curves after shearing at $15 \mathrm{~m}$ at a shear rate of $60 \mathrm{deg} / \mathrm{min}$ and under the normal stresses of $100 \mathrm{kPa}, 200 \mathrm{kPa}$, and $300 \mathrm{kPa}$.

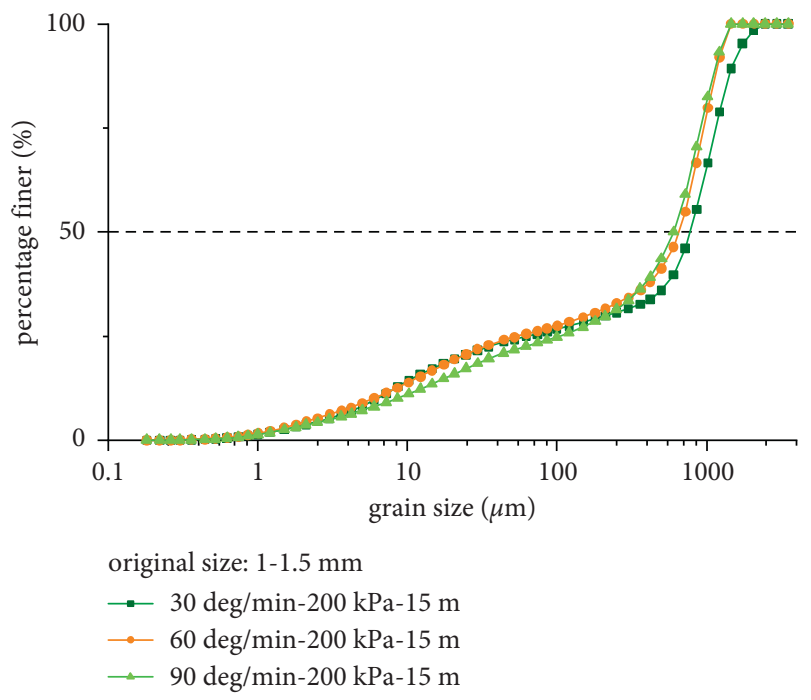

FIGURE 6: Cumulative grain-size distribution curves after shearing at $15 \mathrm{~m}$ at the shear rates of $30 \mathrm{deg} / \mathrm{min}, 60 \mathrm{deg} / \mathrm{min}$, and $90 \mathrm{deg} /$ min under a normal stress of $200 \mathrm{kPa}$.

displacement of less than $10 \mathrm{~m}$, the cumulative grain-size distribution curve shifts to the left as the displacement increases (Figure $7(\mathrm{a})$ ). At the same time, the coarse peak of the frequency grain-size distribution curve also gradually shifts towards the left side, and the fine peak at $15 \mu \mathrm{m}$ becomes more and more apparent (Figure 7(b)). After the shear displacement exceeds $10 \mathrm{~m}$, no significant differences are found in the grainsize distributions (as seen in the curves of $15 \mathrm{~m}$ and $20 \mathrm{~m}$ in Figures $7(\mathrm{a})$ and $7(\mathrm{~b})$ ). In addition, it can be seen that the changes of these curves are mainly attributed to the increase in the powder grade fragments below $80 \mu \mathrm{m}$ (Figure $7(\mathrm{~b})$ ). The most striking result to emerge is that a bimodal distribution develops following a large shear displacement (at $10 \mathrm{~m}$ and above). The fine peaks are about $15 \mu \mathrm{m}$, which is about $1 / 70$ of the original size of the quartz sand. Bimodal distribution is often observed in the shear zone of rock avalanches, as seen in Figure 7(c) [30]. It is worth noting that the cumulative grain-size distributions of $200 \mathrm{kPa}-60 \mathrm{deg} / \mathrm{min}-15 \mathrm{~m}$ in Figures 5(a), 6, and 7(a) are the results of different tests. Similar results indicate that these ring shear tests are stable and credible.

The fractal dimensions of the grain-size distributions were calculated, and the results are shown in Table 3. The coefficient of determination $R^{2}$ is greater than 0.8 , which illustrates that the particle fragmentation under shear conforms to the fractal law. The higher the value of fractal dimension $(F D)$ is, the higher the degree of fragmentation will be [25]. The fractal dimension results for Group A and Group B (Table 3) further indicate that particle fragmentation is related to the normal stress, but not the strain rate. In addition, Group C demonstrates that the FD increases with increasing shear displacement between $3 \mathrm{~m}$ and $15 \mathrm{~m}$. The degree of particle fragmentation increases while the increasing rate of $F D$ decreases. After $15 \mathrm{~m}$ of shear displacement, the fractal dimension reaches 2.5936 , which is only $2 \%$ different from the fractal dimension of 2.6140 at $20 \mathrm{~m}$. The small difference in FD indicates that the degree of fragmentation is basically stable following a large shear displacement.

\subsection{Microscopic Characteristics of Particles under Shearing} Action. 100 coarse particles $(1-1.5 \mathrm{~mm})$ were randomly selected from the samples following different displacements tests and observed under a low-magnification microscope. It is clear that the morphological characteristics of the particles have changed with the shear displacement (Figure 8). Figure 9 quantitatively illustrates the elongation ratio 


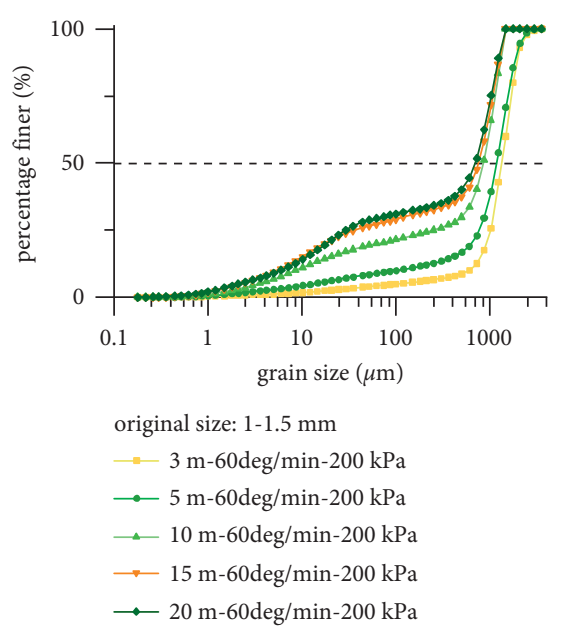

(a)

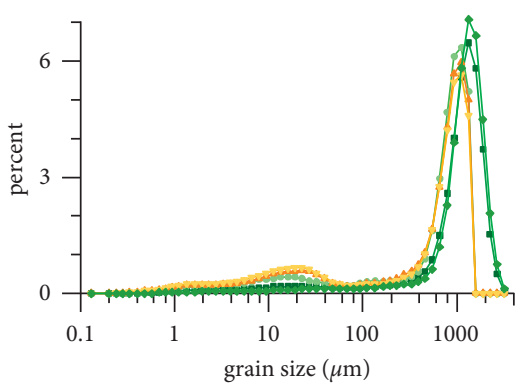

original size: $1-1.5 \mathrm{~mm}$

- $3 \mathrm{~m}-60 \mathrm{deg} / \mathrm{min}-200 \mathrm{kPa}$

- $5 \mathrm{~m}-60 \mathrm{deg} / \mathrm{min}-200 \mathrm{kPa}$

- $10 \mathrm{~m}-60 \mathrm{deg} / \mathrm{min}-200 \mathrm{kPa}$

$\rightarrow 15 \mathrm{~m}-60 \mathrm{deg} / \mathrm{min}-200 \mathrm{kPa}$

- $20 \mathrm{~m}-60 \mathrm{deg} / \mathrm{min}-200 \mathrm{kPa}$

(b)

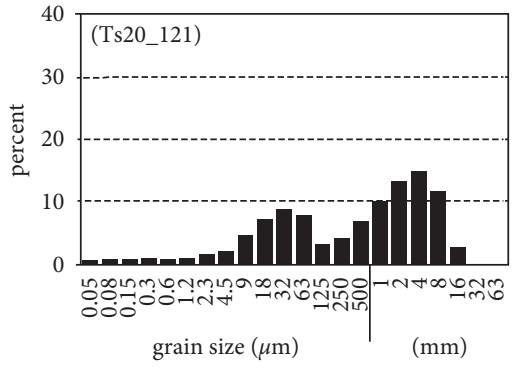

(c)

FIGURE 7: Evolution of grain size distributions with shearing displacements. (a) Cumulative grain-size distribution curves at a shear rate of $60 \mathrm{deg} / \mathrm{min}$ under a normal stress of $200 \mathrm{kPa}$ after shearing at $3 \mathrm{~m}, 5 \mathrm{~m}, 10 \mathrm{~m}, 15 \mathrm{~m}$, and $20 \mathrm{~m}$. (b) Frequency grain-size distribution curves at a shear rate of $60 \mathrm{deg} / \mathrm{min}$ under a normal stress of $200 \mathrm{kPa}$ after shearing at $3 \mathrm{~m}, 5 \mathrm{~m}, 10 \mathrm{~m}, 15 \mathrm{~m}$, and $20 \mathrm{~m}$. (c) Grain-size distribution histograms of the shear zone at Tschirgant showed bimodal distributions [30].

TABLE 3: Fractal dimensions of the different tests.

\begin{tabular}{|c|c|c|c|c|c|}
\hline Group & Normal stress $(\mathrm{kPa})$ & Shear rate $\left(\right.$ deg $\left.\min ^{-1}\right)$ & Shear displacement $(\mathrm{m})$ & Fractal dimension FD & Coefficient of determination $R^{2}$ \\
\hline \multirow{3}{*}{ A } & 100 & & & 1.8600 & 0.8167 \\
\hline & 200 & 60 & 15 & 2.6044 & 0.9058 \\
\hline & 300 & & & 2.7884 & 0.9113 \\
\hline \multirow{3}{*}{ B } & & 30 & & 2.5778 & 0.8621 \\
\hline & 200 & 60 & 15 & 2.5908 & 0.8771 \\
\hline & & 90 & & 2.5730 & 0.9055 \\
\hline \multirow{5}{*}{ C } & & & 3 & 2.0547 & 0.8348 \\
\hline & & & 5 & 2.2813 & 0.8609 \\
\hline & 200 & 60 & 10 & 2.4966 & 0.8364 \\
\hline & & & 15 & 2.5936 & 0.8322 \\
\hline & & & 20 & 2.6140 & 0.8393 \\
\hline
\end{tabular}

and circularity of samples. The mean value of the circularity of the original particles is 0.77 , which is significantly lower than that of the sheared samples (Figure 9(a)). The index of circularity also clearly shows an increasing trend and finally stabilizes at about 0.90 . With the exception of the closer mean values, the homogeneity of the particle morphology was also enhanced (i.e., a decrease in variance). Figure 9(b) shows the change of the elongation ratio, which represents a similar meaning to circularity. The elongation ratio eventually stabilizes at about 1.3 with the shear displacements of $10 \mathrm{~m}$. It is important to note that neither index converges to 1 with shear infinitely and instead both stabilize at a given value.

Figure 10 presents the surface microtextures of quartz sand with the different displacements. A total of 200 quartz sand grains without shearing and $4000.7 \mathrm{~mm}$ fragments $(15 \mathrm{~m})$ were observed. Figure 10 and Table 4, respectively, exhibit the surface microtextures of the unsheared samples (origin particles) and sheared samples $(15 \mathrm{~m})$. The sheared samples exhibit a more angular shape than the unsheared samples. The large conchoidal fractures and parallel steps are highly developed in the original particles, yet significantly reduced in the shear samples. Few smooth surfaces are observed in the original samples, and most of the original particles exhibit high relief. Curved ridges are very common in the original particles, while the sheared samples present clearer and straighter edges. The smooth surfaces, breakage blocks, and small conchoidal fractures appear more frequently in the shear samples.

\section{Discussions}

In response to the previous hypothesis that the crushed finegrained fraction would act as a lubricant to reduce friction [35], the test results of different grain sizes reveal that the reduction of the initial grain size leads to a slight increase in friction (Figure 2). In addition, the shear stress-displacement curves also exhibit no significant decrease in shear stress during shear fragmentation (Figure 3), despite the fact that the grain sizes had become significantly finer $(300 \mathrm{kPa}$, $15 \mathrm{~m})$. Therefore, it is believed that the decrease in the particle size caused by fragmentation does not produce a 


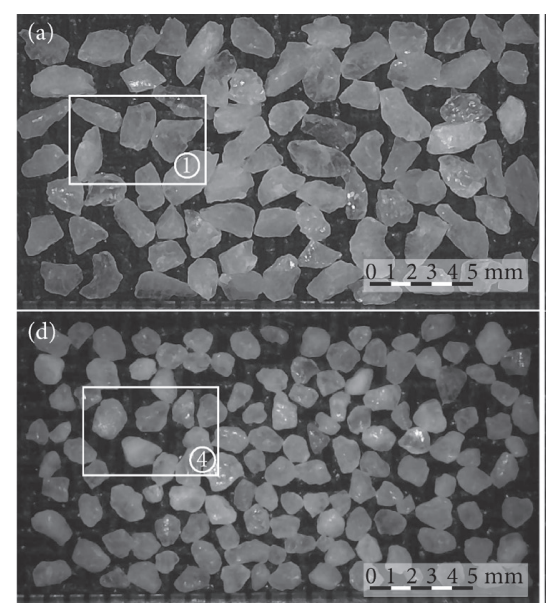

(1)

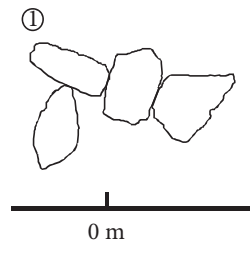

(2)

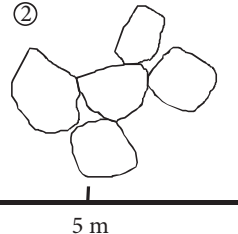

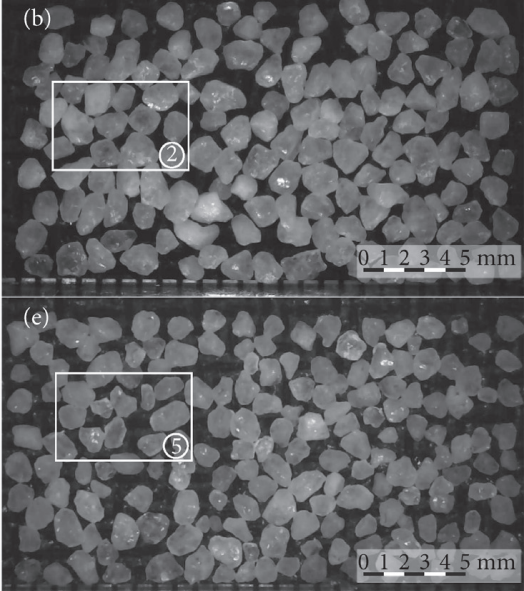
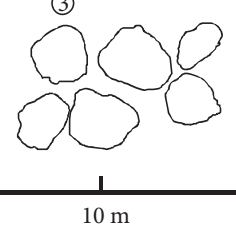

(4)

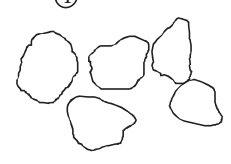

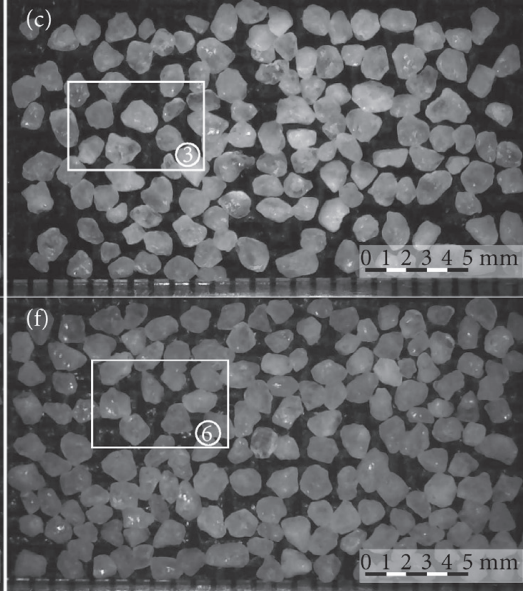

(5)

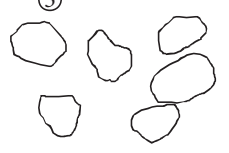

(6)

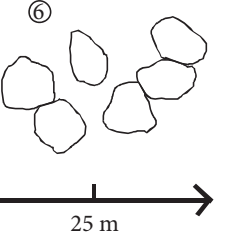

FIGURE 8: Morphometric changes in coarse particles (1-1.5 mm) under shear under optical microscopy.

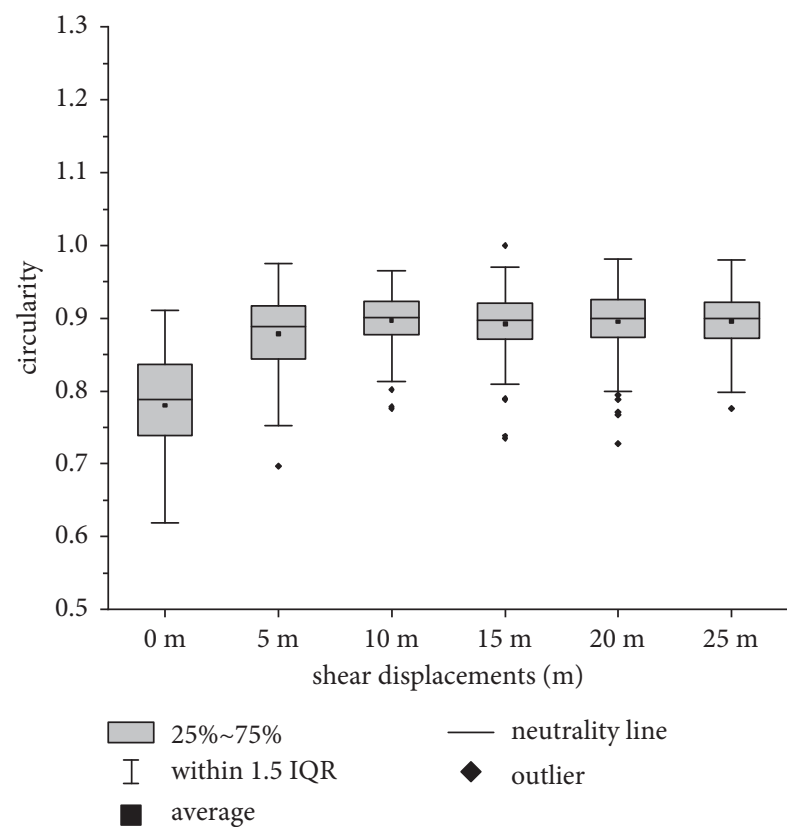

(a)

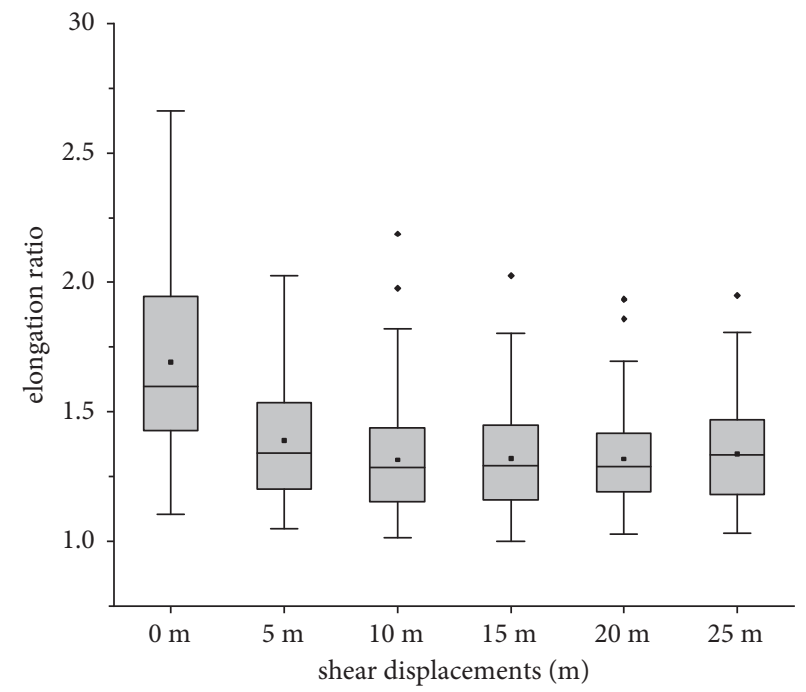

$\square \quad 25 \% \sim 75 \%$
I within $1.5 \mathrm{IQR}$
average

(b)

FIGURE 9: Box plot of circularity variation and elongation change of samples under shear. (a) Circularity of quartz sand after shearing at $0 \mathrm{~m}$, $5 \mathrm{~m}, 10 \mathrm{~m}, 15 \mathrm{~m}, 20 \mathrm{~m}$, and $25 \mathrm{~m}$. (b) Elongation of quartz sand after shearing at $0 \mathrm{~m}, 5 \mathrm{~m}, 10 \mathrm{~m}, 15 \mathrm{~m}, 20 \mathrm{~m}$, and $25 \mathrm{~m}$.

powder lubrication or friction reduction effect during the simple shear process.

All of the shear stress-displacement curves exhibit obvious fluctuation of shear stress (maximum $10 \mathrm{kPa}$ ) during the shearing. However, the statistical results also reveal that the standard deviation or coefficient of variation of the shear stress present no significant change (Table 5), which signifies that the fluctuation is high yet stable throughout the shear process. Therefore, the fluctuation is considered to be caused by the change of the friction in the roll bite rather than fragmentation.

Dynamic fragmentation is an important hypermobility hypothesis $[12,39]$. However, it is difficult to achieve in the laboratory. The major aim of this experiment is to investigate whether fragmentation is the dominant mechanism of hypermobility of rock avalanches, by determining whether 


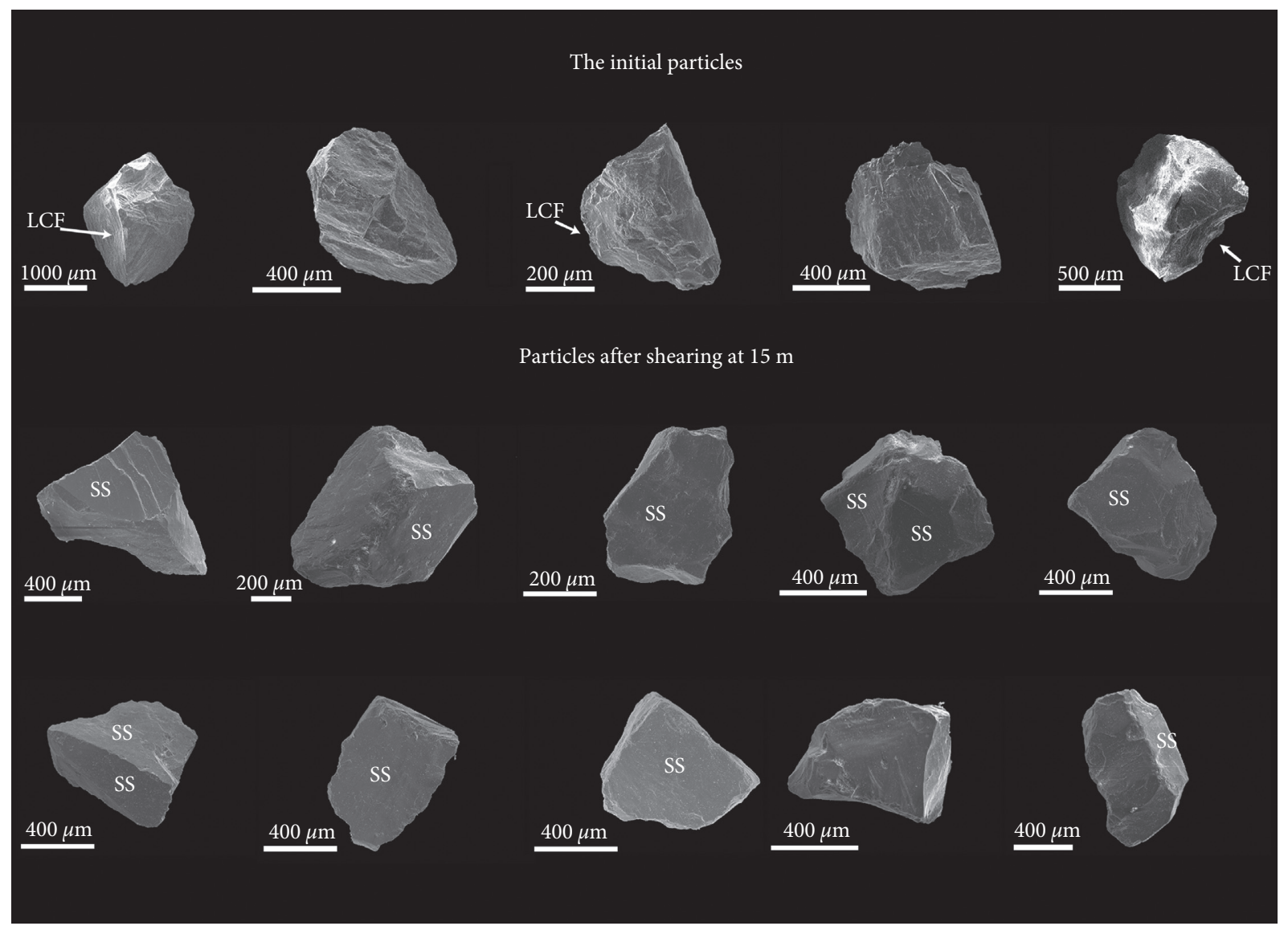

FIGURE 10: Scanning electron microscope images of particles for the original grain sizes and grain sizes larger than $700 \mu \mathrm{m}$ after shearing at $15 \mathrm{~m}$ (SS and LCF, respectively, represent the smooth surface and large conical fracture).

TABLE 4: Variation of surface texture frequency of the quartz sand surfaces.

\begin{tabular}{|c|c|c|c|}
\hline \multicolumn{2}{|l|}{ Original quartz sand } & \multicolumn{2}{|c|}{ Quartz sand after shearing at $15 \mathrm{~m}$} \\
\hline Microtextures & Frequency $(\%)$ & Microtextures & Frequency $(\%)$ \\
\hline (1) Angular outline & 37 & (1) Angular outline & 71 \\
\hline (2) High relief & 89 & (2) High relief & 12 \\
\hline (3) Breakage blocks & 24 & (3) Breakage blocks & 67 \\
\hline (4) Large conchoidal fracture $(>100 \mu \mathrm{m})$ & 53 & (4) Large conchoidal fracture $(>100 \mu \mathrm{m})$ & 19 \\
\hline (5) Parallel steps & 69 & (5) Parallel steps & 37 \\
\hline (6) Smooth surface & 18 & (6) Smooth surface & 86 \\
\hline
\end{tabular}

fragmentation occurs throughout the emplacement process. The results of the grain-size distribution and fractal dimension in this study have provided important insights regarding the characteristics of shear fragmentation. The GSD curves present the breakage of the particles under the shear process, despite the fact that the grain-size distribution curves no longer change significantly following large displacements. The fractal dimension (Figure 11), as a quantitative measure of fragmentation [55], further proves the above finding that the fractal dimension increases with displacement, and the increment decreases gradually (i.e., the slope in Figure 11(c) decreases). This phenomenon indicates that the stable grading caused by shear was indeed present, which signifies that the breakage of particles became very weak and could be ignored following large shear displacements.

Both the GSD and FD show that the degree of fragmentation is sensitive to the change of the normal stresses, which may have been the reason for the variation in GSD in the different positions. In addition, the stable grading displacement of different normal stresses all occurred at around $15 \mathrm{~m}$, which indicates that the effect of the normal stresses on the displacement of the stable shear may not be significant.

Perinotto et al. [35] demonstrated that the grinding limit of collisional crushing (dynamic disintegration) is $500 \mu \mathrm{m}$, while the breakage of particles below $500 \mu \mathrm{m}$ mainly relies on the shear process. However, our results illustrated that the fragmentation during shearing also has a limit. According to 
TABLe 5: Analysis of shear stress-displacement relationship.

\begin{tabular}{|c|c|c|c|c|}
\hline Shear rate & Shear displacement & $0-180 \mathrm{~mm}$ & $180-360 \mathrm{~mm}$ & $360-540 \mathrm{~mm}$ \\
\hline \multirow{3}{*}{$30 \mathrm{deg} / \mathrm{min}$} & Average & 62.82895 & 62.67682 & 62.5622 \\
\hline & Standard deviation & 2.328623 & 2.116855 & 2.511495 \\
\hline & Coefficient of variation & 0.037063 & 0.033774 & 0.040144 \\
\hline \multirow{3}{*}{$60 \mathrm{deg} / \mathrm{min}$} & Average & 63.37705 & 63.27953 & 62.52094 \\
\hline & Standard deviation & 2.525111 & 2.196046 & 2.527427 \\
\hline & Coefficient of variation & 0.039843 & 0.034704 & 0.040425 \\
\hline \multirow{3}{*}{$90 \mathrm{deg} / \mathrm{min}$} & Average & 63.16634 & 62.78268 & 62.62475 \\
\hline & Standard deviation & 3.131989 & 2.655836 & 3.077403 \\
\hline & Coefficient of variation & 0.049583 & 0.042302 & 0.04914 \\
\hline \multirow{3}{*}{$120 \mathrm{deg} / \mathrm{min}$} & Average & 63.63144 & 62.77638 & 62.43142 \\
\hline & Standard deviation & 2.994802 & 2.542645 & 2.926624 \\
\hline & Coefficient of variation & 0.047065 & 0.040503 & 0.046877 \\
\hline
\end{tabular}

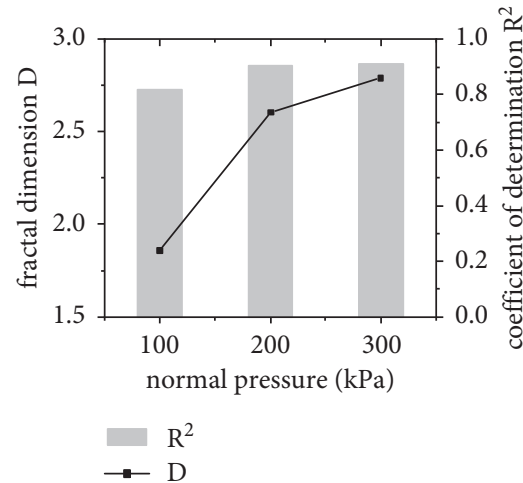

(a)

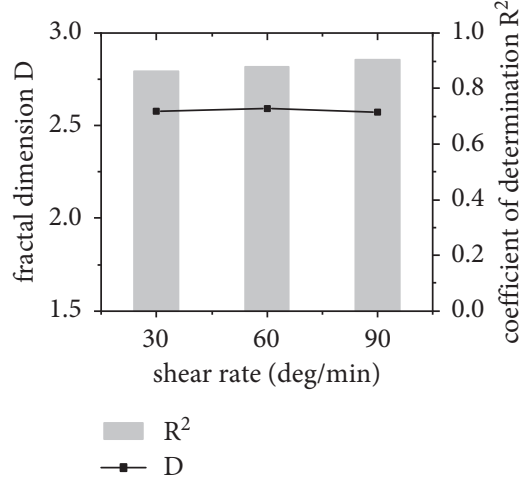

(b)

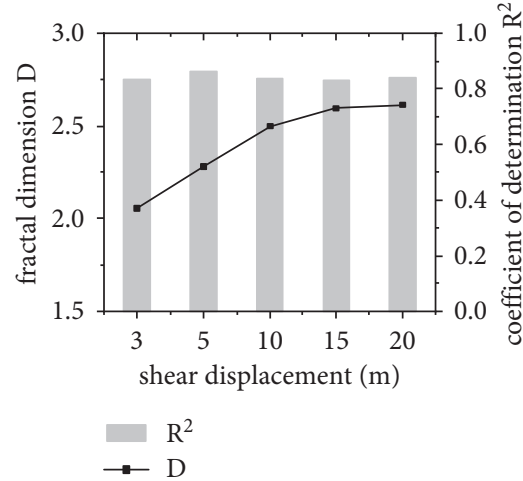

(c)

Figure 11: Fractal dimension under different shear conditions. (a) Fractal dimension after shearing $15 \mathrm{~m}$ at a shear rate of 60 deg/min and normal stresses of $100 \mathrm{kPa}, 200 \mathrm{kPa}$ and $300 \mathrm{kPa}$. (b) Fractal dimension after shearing at $15 \mathrm{~m}$ at a shear rate of $30 \mathrm{deg} / \mathrm{min}, 60 \mathrm{deg} / \mathrm{min}$, and $90 \mathrm{deg} / \mathrm{min}$ under a normal stress of $200 \mathrm{kPa}$. (c) Fractal dimension at a shear rate of $60 \mathrm{deg} / \mathrm{min}$ and a normal stress of $200 \mathrm{kPa}$ after shearing at $3 \mathrm{~m}, 5 \mathrm{~m}, 10 \mathrm{~m}, 15 \mathrm{~m}$, and $20 \mathrm{~m}$.

the results, the stable grading of particles breakage during shearing is considered to appear very quickly $(15 \mathrm{~m})$ compared with the several $\mathrm{km}$ of travel distance in real rock avalanches. This signifies that the material would almost cease breaking soon at the late stage of the emplacement.

It is worth noting that the distinct bimodal distribution of GSD is observed in our tests, which is consistent with that found in the field (Figure 7(c) from Dufresne et al. [30]). Meanwhile, our tests indicated that the bimodal structure did not appear in the early shear stage; then it became more and more obvious as the displacement increased $(>10 \mathrm{~m})$. The bimodal distribution may be responsible for the generation of the stable grading during shearing. Both the field data [30] and the results of this experiment indicated that the grain size of the fine peak is much smaller than the coarse peak. A reasonable explanation for stable grading is that a "wrapping structure" was formed by very fine particles wrapping around the coarse particles. Crosta et al. [25] demonstrated that the increase of the coordination number would reduce the probability of breaking of the coarse particles. In other words, the breaking tends to occur in similar-sized particles $[30,35,56,57]$. For the breakage of the fine particles, the smaller the size is, the more difficult it is to occur. Compared to the field results, in this study the coarse particles maintained a higher content in this study, which may be a result of the higher strength of the quartz sand and smaller normal stress.

Based on the statistical results of the circularity and elongation, the particles were considered mainly reduced along the long axis during the shear process. The morphology of the particles gradually tends to be spherical, which may enhance the ability to resist the shear fragmentation. Both indicators seem to reach a limit at a shear displacement around $10 \mathrm{~m}$, which is basically consistent with the displacement of stable grading, implying that the interparticle action is no longer sufficient to change their geometry. The results of scanning electron microscope also present the morphological changes of the quartz sand during the shear process. Compared with unsheared samples, significant fracture characteristics in sheared samples including the increase of smooth surfaces, fresh sharp edges, and small conchoidal fractures at particle edges were widely observed. All of these morphology changes of the quartz sand indicate that shear fragmentation tends to occur at the edges due to their sharp geometry, where is prone to stress concentration. It is also believed that for other materials, the stress is always 
more concentrated at the edges, and the broken is more likely to occur to produce fine particles, which would produce bimodal distribution to reduce the contact between coarse particles and consequently affect shearing breakage.

This was a series of simplified experiments, and the normal stress used mainly corresponds to a burial depth of $10 \mathrm{~m}$, which is the thickness of the front deposits of some rock avalanches $[11,36,58,59]$. The reason for which we did not use larger normal stress was that there would have been an excessive loss (spillage) of fine particles through the clearances of the equipment. In addition, a roughly linear relationship between shear stress and normal stress was found in this study (Figure 3). Therefore, it is believed that the pattern behavior of this test is applicable to larger normal stresses.

Another limitation of this study was the slow shear rate. Based on the experiments of Zhang and McSaveney [28] as well as the stable grading results in our experiments, ring shear tests with different rates at the shear displacement of $15 \mathrm{~m}$ were performed to investigate the effect of shear rate on the ultimate grain-size distribution. Both our experimental results and those of Zhang and McSaveney showed that the change in shear strain rate does not have a distinct effect on the shear stress or the degree of fragmentation [28] (Figures 4 and 6). However, all of these tests were performed at a lower shear rate. In addition, further systematic experiments on shear rates at different displacements should be conducted in the future. Preview studies regarding the effects of loading rate on rock fracture have illustrated that the increase of loading rate leads to the elevation of more internal joints $[60,61]$. This suggests that high-speed shear compared to low-speed shear may result in more intense breakage, even producing stress waves. In the present study, the ultimate grain-size distribution was considered to have been caused by the wrapping structure, which should also be present in large shear rate tests. Therefore, it is believed that stable grading is also applicable to high-speed shearing.

The grain size range often spans several orders of magnitude, from relatively intact rock prior, to the onset of rock avalanches and to disintegration into debris particles of deposits [62]. Combined with the present experimental features, the fragmentation of rock avalanches is perhaps mainly caused by the premovement collisional effects, including both the impact between the gravity-driven sliding body and the movement path and collisional effects within the individual blocks [25]. In the spreading stage, the materials may have been quickly reached an ultimate grain-size distribution, and the frictional weakening at this stage may have been controlled by mechanisms such as heat vapor effect $[40,63,64]$, or rheological weakening [41], rather than dynamic fragmentation. The main regret of this study is that it does not explain the formation of the discontinuous shear zone, which is significantly finer than other facies.

\section{Conclusions}

The aim of this research was to investigate the shear fragmentation characteristic of dry granular flow, which is important for understanding the fragmentation effect of rock avalanches. Compared with previous studies, regular quartz sand was employed for ring shear tests, and the grainsize distribution and micromorphology were analyzed. Based on the results, the following conclusions were reached:

(1) The stable grading of the shearing process on quartz sand was observed, which indicates that the particles almost ceased breaking following a relatively large displacement. Meanwhile, the results show that the shear friction did not decrease with the increased fineness of the particles, which is consistent with various other grain size comparison tests, indicating powder lubrication may not be the major factor for friction reduction.

(2) The microscopic characteristics and bimodal distribution of sheared samples indicate that the fragmentation of the angular particles develops preferentially on the edges. In addition, the increase of the fine fragments, which are much smaller than the coarse particles (more than 50 times), effectively prevents the breaking of coarse particles, thereby resulting in a stable grading.

(3) The displacement of the stable grading in this study was much smaller than the travel distance of real rock avalanches. Considering the gradual thinning of rock avalanches in the spreading process, it is believed that the violent fragmentation of the rock avalanche no longer occurred in the later stage of the movement (spreading stage). This acts as a challenge to the dynamic fragmentation hypothesis.

(4) Further high-speed ring shear experiments regarding the fragmentation characteristics should be conducted. In addition, the characteristics and formation of the shear zone of the rock avalanches should also be further investigated.

\section{Data Availability}

Some or all data and models that support the findings of this study are available from the corresponding author upon reasonable request.

\section{Conflicts of Interest}

The authors have no conflicts of interest to declare.

\section{Acknowledgments}

This work was supported by the National Key Research and Development Program of China (Grant no. 2018YFC1505003) and the National Natural Science Foundation of China (Grant no. 41571012). The authors would like to sincerely thank Dr. Dewen Li and Dr. Linlin Li from National Institute of Natural Hazards of China for their assistance with the experiments.

\section{References}

[1] S. A. Dunning, Rock avalanche in high mountains, $\mathrm{PhD}$ thesis, University of Luton, Luton, UK, 2004.

[2] O. Hungr and S. G. Evans, "Entrainment of debris in rock avalanches: an analysis of a long run-out mechanism," The 
Geological Society of America Bulletin, vol. 116, no. 9-10, pp. 1240-1252, 2004.

[3] A. Heim, "Der bergsturz von elm," Zeitschrift der Deutschen Geologischen Gesellschaft, vol. 34, no. 1, pp. 74-115, 1882.

[4] F. Legros, "The mobility of long-runout landslides," Engineering Geology, vol. 63, no. 3, pp. 301-331, 2002.

[5] R. L. Shreve, "Leakage and fluidization in air-layer lubricated avalanches," The Geological Society of America Bulletin, vol. 79, no. 5, pp. 653-658, 1968.

[6] M. Zhang, Y. Yin, S. Wu, Y. Zhang, and J. Han, "Dynamics of the niumiangou creek rock avalanche triggered by $2008 \mathrm{Ms}$ 8.0 wenchuan earthquake, sichuan, China," Landslides, vol. 8, no. 3, pp. 363-371, 2011.

[7] L. Masch, H. R. Wenk, and E. Preuss, "Electron microscopy study of hyalomylonites-evidence for frictional melting in landslides," Tectonophysics, vol. 115, no. 1-2, pp. 131-160, 1985.

[8] F. V. De Blasio and A. Elverhøi, "A model for frictional melt production beneath large rock avalanches," Geophysical Research: Earth Surface, vol. 113, no. F2, 2008.

[9] W. Hu, R. Huang, M. McSaveney et al., "Superheated steam, hot $\mathrm{CO} 2$ and dynamic recrystallization from frictional heat jointly lubricated a giant landslide: field and experimental evidence," Earth and Planetary Science Letters, vol. 510, pp. 85-93, 2019.

[10] Y.-F. Wang, Q.-G. Cheng, A.-W. Shi, Y.-Q. Yuan, Y.-H. Qiu, and B.-M. Yin, "Characteristics and transport mechanism of the Nyixoi Chongco rock avalanche on the Tibetan Plateau, China," Geomorphology, vol. 343, pp. 92-105, 2019.

[11] Q. Zeng, L. Zhang, T. Davies et al., "Morphology and inner structure of Luanshibao rock avalanche in Litang, China and its implications for long-runout mechanisms," Engineering Geology, vol. 260, Article ID 105216, 2019.

[12] T. R. Davies and M. J. McSaveney, "The role of rock fragmentation in the motion of large landslides," Engineering Geology, vol. 109, no. 1-2, pp. 67-79, 2009.

[13] M. J. McSaveney and T. R. Davies, "Surface energy is not one of the energy losses in rock comminution," Engineering Geology, vol. 109, no. 1-2, pp. 109-113, 2009.

[14] E. T. Bowman, W. A. Take, K. L. Rait, and C. Hann, "Physical models of rock avalanche spreading behaviour with dynamic fragmentation," Canadian Geotechnical Journal, vol. 49, no. 4, pp. 460-476, 2012.

[15] H. J. Melosh, "Acoustic fluidization," American Scientist, vol. 71, no. 2, pp. 158-165, 1983.

[16] G. S. Collins and H. J. Melosh, "Acoustic fluidization and the extraordinary mobility of sturzstroms," Journal of Geophysical Research: Solid Earth, vol. 108, no. B10, 2003.

[17] W. V. Gassen and D. M. Cruden, "Momentum transfer and friction in the debris of rock avalanches," Canadian Geotechnical Journal, vol. 26, no. 4, pp. 623-628, 1989.

[18] Q. Zeng, J. Zhu, L. Liao et al., "High mobility of the channelized ancient Linka rock avalanche within the Bangong - nujiang suture zone, SE Tibetan Plateau," Engineering Geology, vol. 282, no. 3, Article ID 105999, 2021.

[19] T. R. Davies, M. J. McSaveney, and K. A. Hodgson, "A fragmentation-spreading model for long-runout rock avalanches," Canadian Geotechnical Journal, vol. 36, no. 6, pp. 1096-1110, 1999.

[20] M. J. McSaveney and T. R. H. Davies, "Rapid rock mass flow with dynamic fragmentation: inferences from the morphology and internal structure of rockslides and rock avalanches," Landslides, vol. 49, pp. 285-304, 2006.
[21] T. R. H. Davies, M. J. McSaveney, and A. M. Deganutti, "Dynamic rock fragmentation causes low rock-on-rock friction: dynamic rock fragmentation causes low rock-onrock friction," in Proceedings of the 1st Canada-U.S, pp. 27-31, Rock Mechanics Symposium, Vancouver, Canada, 2007.

[22] F. V. De Blasio, "Friction and dynamics of rock avalanches travelling on glaciers," Geomorphology, vol. 213, pp. 88-98, 2014.

[23] T. R. H. Davies, N. V. Reznichenko, and M. J. McSaveney, "Energy budget for a rock avalanche: fate of fracture-surface energy," Landslides, vol. 17, no. 17, pp. 3-13, 2020.

[24] B. Bai, G. C. Yang, T. Li, and G. S. Yang, "A thermodynamic constitutive model with temperature effect based on particle rearrangement for geomaterials," Mechanics of Materials, vol. 139, Article ID 103180, 2019.

[25] G. B. Crosta, P. Frattini, and N. Fusi, "Fragmentation in the val pola rock avalanche, Italian alps," Journal of Geophysical Research Earth Surface, vol. 112, no. F1, 2007.

[26] F. V. De Blasio, "Rheology of a wet, fragmenting granular flow and the riddle of the anomalous friction of large rock avalanches," Granular Matter, vol. 11, no. 3, pp. 179-184, 2009.

[27] D. H. Shugar and J. J. Clague, "The sedimentology and geomorphology of rock avalanche deposits on glaciers," Sedimentology, vol. 58, no. 7, pp. 1762-1783, 2011.

[28] M. Zhang and M. J. McSaveney, "Rock avalanche deposits store quantitative evidence on internal shear during runout," Geophysical Research Letters, vol. 44, no. 17, pp. 8814-8821, 2017.

[29] M. Charrière, F. Humair, C. Froese, M. Jaboyedoff, A. Pedrazzini, and C. Longchamp, "From the source area to the deposit: collapse, fragmentation, and propagation of the Frank Slide," The Geological Society of America Bulletin, vol. 128, pp. 332-351, 2016.

[30] A. Dufresne, A. Bösmeier, and C. Prager, "Sedimentology of rock avalanche deposits - case study and review," EarthScience Reviews, vol. 163, pp. 234-259, 2016.

[31] D. M. Cruden and O. Hungr, "The debris of the Frank Slide and theories of rockslide-avalanche mobility," Canadian Journal of Earth Sciences, vol. 23, no. 3, pp. 425-432, 1986.

[32] S. A. Dunning and P. J. Armitage, "The grain-size distribution of rock-avalanche deposits: implications for natural dam stability," Natural and Artificial Rockslide Dams, vol. 133, no. 1, pp. 479-498, 2011.

[33] A. Dufresne and S. A. Dunning, "Process dependence of grain size distributions in rock avalanche deposits," Landslides, vol. 14, no. 5, pp. 1555-1563, 2017.

[34] K. Hewitt, "Catastrophic rockslides and the geomorphology of the hunza and gilgit river valleys, Karakoram Himalaya," Erdkunde, vol. 55, no. 1, pp. 72-93, 2001.

[35] H. Perinotto, J. L. Schneider, P. Bachèlery, F. Bourdonnec, and L. Michon, "The extreme mobility of debris avalanches: a new model of transport mechanism," Journal of Geophysical Research: Solid Earth, vol. 120, no. 12, pp. 8110-8119, 2006.

[36] Z. Ren, K. Wang, K. Yang et al., "The grain size distribution and composition of the Touzhai rock avalanche deposit in Yunnan, China," Engineering Geology, vol. 234, pp. 97-111, 2018.

[37] J.-Y. Luo, Z.-M. Xu, Z. Ren et al., "Rock avalanche-debris geometry and implications for rock-avalanche genesis," Geomorphology, vol. 334, pp. 60-75, 2019.

[38] J. Chen, R. C. Chen, D. D. Mi, X. X. Zheng, and Y. C. Gao, "Kinematic processes and fragmentation characteristics of Walai rock avalanche landslide in Tibet," Advanced Engineering Sciences, vol. 56, no. 6, pp. 30-39, 2020. 
[39] Y. Jiang, G. Wang, and T. Kamai, "Fast shear behavior of granular materials in ring-shear tests and implications for rapid landslides," Acta Geotechnica, vol. 12, no. 3, pp. 645-655, 2017.

[40] Y. F. Wang, J. J. Dong, and Q. G. Cheng, "Velocity-dependent frictional weakening of large rock avalanche basal facies: implications for rock avalanche hypermobility," Journal of Geophysical Research: Solid Earth, vol. 122, no. 3, pp. 1648-1676, 2017.

[41] W. Hu, C. S. Chang, M. McSaveney et al., "A weakening rheology of dry granular flows with extensive brittle grain damage in high-speed rotary shear Experiments," Geophysical Research Letters, vol. 47, no. 11, 2020.

[42] A. N. Dubovskoi, L. M. Pernik, and A. L. Strom, "Experimental simulation of rockslide fragmentation," Journal of Mining Science, vol. 44, no. 2, pp. 123-130, 2008.

[43] M. Zhang, Y. Yin, and M. McSaveney, "Dynamics of the 2008 earthquake-triggered wenjiagou creek rock avalanche, qingping, sichuan, China," Engineering Geology, vol. 200, pp. 75-87, 2016.

[44] M. R. Coop, K. K. Sorensen, T. Bodas Freitas, and G. Georgoutsos, "Particle breakage during shearing of a carbonate sand," Géotechnique, vol. 54, no. 3, pp. 157-163, 2004.

[45] B. Bai, R. Zhou, G. Q. Cai, W. Hu, and G. C. Yang, "Coupled thermo-hydro-mechanical mechanism in view of the soil particle rearrangement of granular thermodynamics," Computers and Geotechnics, vol. 137, no. 8, Article ID 104272, 2021.

[46] B. Bai, L. Guo, and S. Han, "Pore pressure and consolidation of saturated silty clay induced by progressively heating/cooling," Mechanics of Materials, vol. 75, pp. 84-94, 2014.

[47] C.-X. Tong, G. J. Burton, S. Zhang, and D. Sheng, "Particle breakage of uniformly graded carbonate sands in dry/wet condition subjected to compression/shear tests," Acta Geotechnica, vol. 15, no. 9, pp. 2379-2394, 2020.

[48] K. Vos, N. Vandenberghe, and J. Elsen, "Surface textural analysis of quartz grains by scanning electron microscopy (SEM): from sample preparation to environmental interpretation," Earth-Science Reviews, vol. 128, pp. 93-104, 2014.

[49] R. Chen, J. Chen, J. Ma, and Z. Cui, "Quartz grain surface microtextures of dam-break flood deposits from a landslidedammed lake: a case study," Sedimentary Geology, vol. 383, pp. 238-247, 2019.

[50] H. Xie and W. G. Pariseau, "Fractal character and mechanism of rock bursts," International Journal of Rock Mechanics and Mining Sciences \& Geomechanics Abstracts, vol. 30, no. 4, pp. 343-350, 1993.

[51] E. P. Cox, "A method of assigning numerical and percentage values to the degree of roundness of sand grains," Journal of Paleontology, vol. 1, no. 3, pp. 179-183, 1927.

[52] P. J. M. Costa, C. Andrade, A. G. Dawson et al., "Microtextural characteristics of quartz grains transported and deposited by tsunamis and storms," Sedimentary Geology, vol. 275-276, pp. 55-69, 2012.

[53] W. C. Mahaney, Atlas of Sand Grain Surface Textures and Applications, Oxford, New York, NY, USA, 2002.

[54] M. O. Molén, "A simple method to classify diamicts by scanning electron microscope from surface microtextures," Sedimentology, vol. 61, no. 7, pp. 2020-2041, 2014.

[55] E. Perfect, "A simple method to classify diamicts by scanning electron microscope from surface microtextures," Engineering Geology, vol. 48, no. 3, pp. 185-198, 1997.
[56] R. A. Bagnold, "Experiments on a gravity-free dispersion of large solid spheres in a Newtonian fluid under shear," Proceedings of the Royal Society of London: Mathematical, Physical and Engineering Sciences, vol. 225, no. 1160, pp. 49-63, 1954.

[57] K. J. Hsü, "Catastrophic debris streams (sturzstroms) generated by rockfalls," The Geological Society of America Bulletin, vol. 86, no. 1, pp. 1291-1240, 1975.

[58] Y.-F. Wang, Q.-G. Cheng, Q.-W. Lin, K. Li, and H.-F. Yang, "Insights into the kinematics and dynamics of the Luanshibao rock avalanche (Tibetan Plateau, China) based on its complex surface landforms," Geomorphology, vol. 317, pp. 170-183, 2018.

[59] Y. Zhu, F. Dai, and X. Yao, "Preliminary understanding of the emplacement mechanism for the Tahman rock avalanche based on deposit landforms," The Quarterly Journal of Engineering Geology and Hydrogeology, vol. 53, no. 3, pp. 460-465, 2019.

[60] Z. X. Zhang, S. Q. Kou, J. Yu, Y. Yu, L. G. Jiang, and P.-A. Lindqvist, "Effects of loading rate on rock fracture," International Journal of Rock Mechanics and Mining Sciences, vol. 36, no. 5, pp. 597-611, 1999.

[61] H. Y. Pan, D. Ge, T. J. Zhang, X. G. Dong, L. Zhang, and A. Zhou, "Influence of strain rate on the rock fracture propagation law," Journal of China Coal Society, vol. 43, no. 3 , pp. 675-683, 2018.

[62] K. Hewitt, J. J. Clague, and J. F. Orwin, "Legacies of catastrophic rock slope failures in mountain landscapes," EarthScience Reviews, vol. 87, no. 1-2, pp. 1-38, 2008.

[63] B. Bai, Q. K. Nie, Y. K. Zhang, X. L. Wang, and W. Hu, "Cotransport of heavy metals and $\mathrm{SiO} 2$ particles at different temperatures by seepage," Journal of Hydrology, vol. 597, Article ID 125771, 2021.

[64] S. Boutareaud, A. M. Boullier, M. Andréani et al., "Clay clast aggregates in gouges: new textural evidence for seismic faulting," Journal of Geophysical Research: Solid Earth, vol. 115, Article ID B02408, 2010. 